\title{
Managing Eclampsia in a Medical College
}

\author{
RC LK ${ }^{1}$, Shrestha $\mathbf{S}^{2}$, Das $\mathbf{C R}^{2}$ \\ ${ }^{1}$ Department of Obstetrics and Gynaecology, Patan Academy of Health Sciences, Lalitpur \\ ${ }^{2}$ Department of Obstetrics and Gynaecology, Nepalgunj Medical College, Kohalpur.
}

\begin{abstract}
Aims: The aim was to analyze patient's age, gestational age, mode of delivery, types of complication, fetomaternal outcome and prognosis in eclampsia.

Methods: This was a retrospective one year study done at Nepalgunj medical college from June 2009 to May 2010.

Results: Out of $21(1.11 \%)$ eclampsia, nine $(42.85 \%)$ were $<20$ years, nine $(42.85 \%)$ were at term and $15(71.43 \%)$ were primi para. Systolic blood pressure recorded $>160 \mathrm{~mm} \mathrm{Hg}$ in eight (38.10\%) and diastolic blood pressure recorded $91-100 \mathrm{~mm} \mathrm{Hg}$ were nine (42.8\%). Antepartum and intrapartum eclampsia were $18(85.72 \%)$ and two $(9.52 \%)$ respectively. Nine $(42.86 \%)$ had lower segment cesarean section. Ten $(47.62 \%)$ babies were alive. All the patients were treated with magnesium sulphate and survived.
\end{abstract}

Conclusions: Most of the patients in this study were primi para at term pregnancy. Patients were treated with magnesium sulphate that prevented maternal mortality.

Keywords: eclampsia, high blood pressure, magnesium sulphate, preeclampsia.

\section{INTRODUCTION}

The onset of convulsions in a woman with preeclampsia not attributed to other causes is termed eclampsia. The seizures are generalized appearing before, during, or after labour. ${ }^{1}$

It typically occurs during or after $20^{\text {th }}$ week of gestation or in postpartum period. Eclampsia in absence of hypertension with proteinuria has been demonstrated to occur in $38 \%$ in the United Kingdom. ${ }^{2}$ Similarly, hypertension was absent in $16 \%$ of cases in the United States. ${ }^{3}$ Genetic predisposition, immunology, endocrinology, abnormal trophoblastic invasion, coagulation abnormalities, vascular endothelial damage and various other causes have been proposed as etiologic factors for preeclampsia/eclampsia. ${ }^{4}$ Imbalanced prostanoid production and increased

\section{CORRESPONDENCE}

Dr Laxmi RC (Karki)

Department of Obstetrics and Gynecology, Patan Academy of Health Sciences, Lalitpur

Email: dr_lax50@hotmail.com

Phone: $+\overline{9} 77-9851085326$ plasma antiphospholipids have also been implicated in eclampsia. ${ }^{5,6}$

Eclampsia is a very serious but preventable complication of pregnancy responsible for high maternal and perinatal mortality. So this study was conducted to see different factors associated with eclampsia.

\section{METHODS}

A retrospectivestudy was carried out in the Department of Obstetrics and Gynaecology, Nepalgunj Medical College, Kohalpur from June 2009 to May 2010. We analyzed patient's age, gestational age, mode of delivery and types of complication, fetomaternal outcome and prognosis. Ethical approval was taken from the hospital authority. Informed consent was obtained from the patients. The charts were collected from medical record section and analyzed.

All the patients were treated with magnesium sulphate for controlling fit and sublingual (because other drugs were not available) administration of calcium channel 
blocker for controlling hypertension. Nutrition and fluid balance were maintained. Complications were managed as per hospital protocol. For obstetric management in both primi and multi gravida, the patients were separated in two groups after pelvic assessment: those with favourable Bishop score $(\geq 6)$ and those with unfavourable Bishop score $(\leq 5)$. Patients with favorable Bishop Score were selected for induction of labour (by misoprostol, artificial rupture of membrane and oxytocinon) and those with unfavorable Bishop score underwent lower segment cesarean section. Each patient was followed till discharge.

\section{RESULTS}

There were 1885 deliveries at Nepalgunj Medical College, Kohalpur during the study period and 21 $(1.11 \%)$ women presented with eclampsia.

Regarding gestational age of the patients on admission nine patients $(42.86 \%)$ were above 37 weeks of pregnancy and seven $(33.33 \%)$ were at $32-37$ weeks of pregnancy. Nine patients $(42.86 \%)$ underwent lower segment cesarean section due to foetal bradycardia and non-progress of labaour, seven (33.33\%) had spontaneous vaginal delivery, three $(14.29 \%)$ needed forceps delivery and two $(10 \%)$ had vacuum delivery. In this study ten $(47.62 \%)$ babies were alive, among them six $(28.57 \%)$ were born by cesarean section and two $(9.52 \%)$ by spontaneous vaginal delivery. There were five $(23.8 \%)$ still-births and six $(28.57 \%)$ neonatal deaths. The remarkable complications were fever and preterm labor, three $(14.29 \%)$ in each; postpartum hemorrhage in two $(9.52 \%)$ and wound infection in one $(4.76 \%)$.

There were no maternal deaths and eight patients $(38.10 \%)$ had no complications.

Table 1. Age distribution $(\mathrm{n}=\mathbf{2 1})$.

\begin{tabular}{lll}
\hline Age in years & Primi gravida & Multigravida \\
\hline $15-19$ & 09 & 01 \\
$20-24$ & 04 & 03 \\
$25-29$ & 02 & - \\
$30-34$ & - & 02 \\
$>35$ & - & - \\
\hline
\end{tabular}

The age of the patients ranged from 15 to 35 years. Out of 21 cases, nine cases of primi gravida and one case of multi gravida were in the age group 15 to 19 years, four cases of primi gravida and one case of multi gravida in age group of 20 to 24 years, two cases of primi gravid and two cases of multi gravid in the age group of 25 to 29 and 30 to 34 years respectively.

Table 2. Systolic blood pressure (BP) at admission $(n=21)$.

\begin{tabular}{|c|c|}
\hline Systolic BP $\mathrm{mmHg}$ & Number $(\%)$ \\
\hline 140 & $05(23.81)$ \\
\hline $141-150$ & $06(28.57)$ \\
\hline $151-160$ & $02(9.52)$ \\
\hline$\geq 160$ & $08(38.10)$ \\
\hline
\end{tabular}

Systolic blood pressure more than $160 \mathrm{~mm} / \mathrm{Hg}$ was found in eight cases $(38 \%)$.

Table 3. Diastolic Blood pressure at admission $(n=21)$.

\begin{tabular}{ll}
\hline Diastolic BP $(\mathrm{mmHg})$ & $\begin{array}{l}\text { Percentage } \\
(\%)\end{array}$ \\
\hline 90 & $03(14.29)$ \\
$91-100$ & $09(42.86)$ \\
$101-110$ & $04(19.04)$ \\
$>110$ & $05(23.81)$ \\
\hline
\end{tabular}

Diastolic blood pressure than 91 to $100 \mathrm{~mm} / \mathrm{Hg}$ was found nine cases $(42 \%)$.

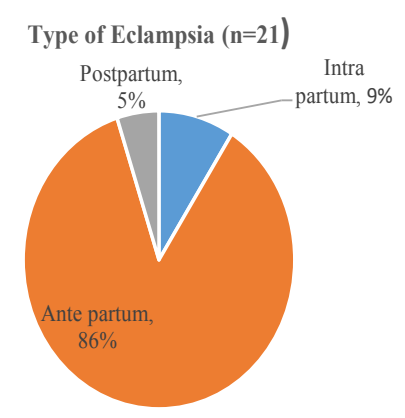

- Intra partum = Ante partum = Postpartum

Figure 1. Type of eclampsia.

Maximum number of patients belonged to antepartum eclampsia. 


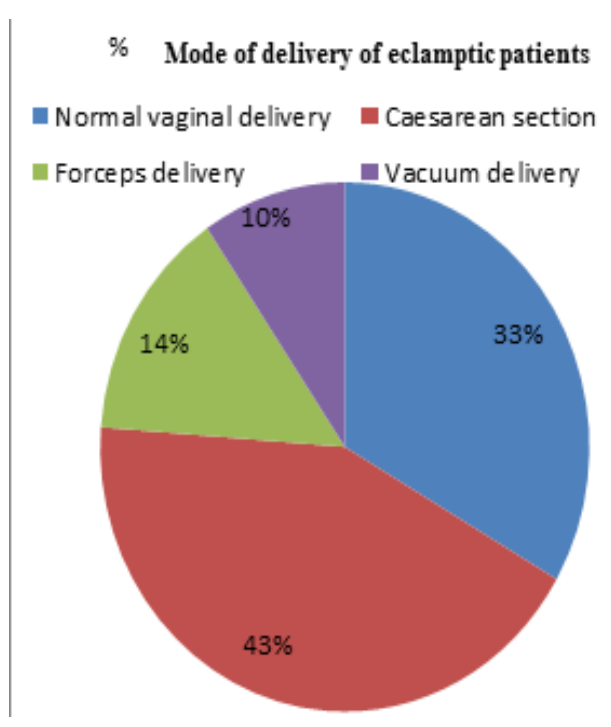

Figure 2. Mode of delivery.

Most of our patients had caesarean section.

Table 4. Perinatal outcome $(n=21)$.

\begin{tabular}{ll}
\hline Outcome & Number $(\%)$ \\
\hline Alive & $10(47.62)$ \\
Still birth & $05(23.80)$ \\
Neonatal Death & $06(28.58)$ \\
\hline
\end{tabular}

Ten babies (47.6\%) were alive. Five babies $(23.80 \%)$ were presented with still birth during admission and six babies (28.58\%) had neonatal deaths due to birth asphyxia and pneumonia.

\section{DISCUSSION}

Eclampsia is a very serious hypertensive disorder of pregnancy. Both maternal and perinatal mortalities are high in spite of the different preventive approaches like safe motherhood to improve obstetric care in Nepal. Eclampsia usually occurs in patients at both extremes of reproductive age however the risk of eclampsia is greatest in women younger than 20 years. $^{7-10}$.

Among the live birth, APGAR score rating were compared, caesarean section group had better APGAR rating than vaginal delivery section group. But opposite result was found in other studies. ${ }^{10,11}$ Perinatal mortality was higher in vaginal delivery group three $(14.28 \%)$ than csesarean section group one $(4.76 \%)$.
A Chinese study showed $55.66 \%$ caesarean delivery but in our study there were nine $(43 \%)$. ${ }^{11}$ Several studies have concluded that high perinatal mortality/ morbidity is associated with babies born to eclampsic mothers. In our study also we had six (28.58\%) neonatal deaths. Unlike the Cambodian study of $20 \%$ still birth our still birth rate was five (23.8\%). Studies in Thailand and India have quoted a high cesarean section rate, associated with better peri-natal outcome. Even though our operative rate was nine (43\%) compared to $57 \%$ in Thailand, or $79 \%$ in Nova Scotia, the perinatal outcomes were ten $(47.62 \%)$ not bad in comparison to the two. ${ }^{12}$ Incidence of eclampsia is high in countries of South East Asia and Africa have a higher incidence as compared to the The incidence in the West. ${ }^{12-18}$

The incidence of eclampsia at Koshi Zonal Hospital was $1.2 \%$ similar like our study $21(1.11 \%){ }^{19}$

If we want to reduce the maternal and perinatal mortality we should improve the socio economic condition, there is a great need for public health education expansion of education and training of personnel in the best professional techniques of maternal and neonatal care. When eclampsia is established, immediate hospitalization with best available nursing care and medical management with early termination of pregnancy should be done. If vaginal delivery is not anticipated shortly, caesarean section should be performed after correcting the haemodynamic status in best possible set up, only then the desired results can be achieved.

\section{CONCLUSIONS}

Most of the patients in this study were primi para at term pregnancy. All the patients were treated with magnesium sulphate that prevented maternal mortality and most patients underwent caesarean section for delivery.

\section{ACKNOWLEDGEMENT}

This work was supported by Mr Tarka Malla working in statistic section in Nepalgunj Medical College, Kohalpur.

\section{DISCLOSURE}

The authors report no conflicts of interest in this work.

No violation of human rights and safety.

Funding: Nil 


\section{REFERENCES}

1. Pregnancy Hypertension. In: Cunningham FG, Leveno KJ, Bloom SL, Hauth JC, Rouse DJ et al, editors. Wlliams obstetrics. 23rd ed. United States of America: McGraw Hill companies; 2010. p.706.

2. Douglas KA, Redman CW. Eclampsia in the United Kingdom. BMJ. 1994;309(6966): 1395-400.

3. Mattar F, Sibai BM. Eclampsia: risk factors for maternal morbidity. Am J Obstet Gynecol. 1990;163:1049-55.

4. Gabbe SG. Obstetrics: Normal and Problem Pregnancies. In: Sibai BM. Hypertension. 5th ed. Philadelphia; Churchill Livingstone: An Imprint of Elsevier. 2007.

5. Nodler J, Moolamalla SR, Ledger EM, Nuwayhid BS Mulla ZD. Elevated antiphospholipid antibody titers and adverse pregnancy outcomes: analysis of a populationbased hospital dataset. BMC Pregnancy Childbirth. 2009;9:11.

6. Reddy A, Suri S, Sargent IL, Redman CW, Muttukrishna S. Maternal circulating levels of activin A, inhibin A, sFlt1 and endoglin at parturition in normal pregnancy and preeclampsia. PLoS One. 2009;4(2):4453.

7. Khanum M, Ashref F, Sahrin H. A clinical study of 100 cases of eclampsia in Rajshahi medical college hospital. The Journal of Teachers Association RMC Rajshahi. 2004;17(2):80-3.

8. Tencer CE, Hakverdi AU, Aban M, Erden AC, Ozelbaykal U. Prevalence, management and outcome in eclampsia. Int J Gynaecol Obstet. 1996;53(1):11-5.

9. Porapakkham S. An epidemilogic study of eclampsia Obstet Gynaecol. 1979;54(1):26-30

10. Khatun S, Nilufer S, Bhuiyn AB, Begum K. Perinatal outcome in eclampsia: Bangladesh. J Obstet Gynaecol. 1994:9:53-60.

11. Luan JQ. The treatment of eclampsia by early interruption of pregnancy: a 15-year review. Asia Oceania J Obstet Gynaecol. 1989;15(1):33-5.

12. Lee w, O'connel CM, Baskett TF. Maternal and prenatal outcomes of eclampsia: Nova Scotia. J Obstet Gnaecol. 2004;26(2):119-23

13. Begum R, Begum A, Bullough CH, Johanson RB. Reducing maternal mortality from eclampsia, using magnesium sulphate. Eur J Obstet Gynecol. 2000;92(2):223-4.

14. Sawhney H, Aggarwal N, Biswas R, Vasishta K, Gopalan S. Maternal mortality associated with eclampsia and severe preeclampsia of pregnancy. J Obstet Gynecol. 2000;26(5):351-6.

15. Which anticonvulsant for women with eclampsia? Evidence from the collaborative eclampsia trial. Lancet 2001;357(9252):312.

16. Witlin AG, Sibai BM. Magnesium sulphate therapy in preeclampsia and eclampsia. Obstet Gynecol. 1998;92(5):883-9.

17. Azria E, Tsatsaris V, Goffinet F, Kayem G, Mignon A, Cabrol D. Magnesium sulphate in obstetrics:current data. J Obstet Gynecol. 2004;33(6):510-7.

18. Gessessew A. Maternal complications in a zonal hospital. Ethiop Med J. 2007;45(1): 4754.

19. Thapa K, Jha R. Magnesium sulphate: a life saving drug. J Nepal Med Assoc. 2008;47(171):104-8. 